\title{
FUNIL MIDIÁTICO: RETRATO DA PRESENÇA DAS AGÊNCIAS DE NOTÍCIAS NACIONAIS NO JORNALISMO BRASILEIRO DE NORTE A SUL
}

\author{
MEDIA FUNNEL: PORTRAIT OF THE PRESENCE OFNATIONAL NEWS \\ AGENCIES IN BRAZILIAN JOURNALISM FROM NORTH TO SOUTH \\ EMBUDO DE MEDIOS: RETRATO DE PRESENCIA DE LAS AGENCIAS \\ DE PRENSA NACIONALES EN EL PERIODISMO BRASILEÑO \\ DE NORTE A SUR
}

\author{
Hebe M. Gonçalves de Oliveira \\ Dra., UEPG \\ hebegoncalves@hotmail.com
}

\begin{abstract}
Resumo: Este artigo mostra a presença das agências de notícias nacionais em 10 diferentes jornais sediados nas principais capitais brasileiras, de forma a traçar um retrato do jornalismo brasileiro que se coloca dependente dos serviços noticiosos dos três maiores grupos de mídia impressa do País - O Estado de S. Paulo, Folha de S. Paulo e O Globo -, que selecionam temas e geram conteúdos, interpretações e análises dos fatos não só para suas edições diárias, mas através de suas próprias agências, alimentam jornais em diversas regiões do País. A pesquisa se orienta pela perspectiva da sociologia das redações, que concentra um conjunto de estudos como newsmaking e gatekeeping, com o objetivo de compreender o modus operandi e atuação das agências de notícias nacionais no jornalismo brasileiro.
\end{abstract}

Palavras-chave: agências de notícias nacionais, jornalismo regional, conglomerados de mídia

Abstract:This article shows the presence of national news agencies in 10 different newspapers in major Brazilian cities, in order to draw a portrait of Brazilian journalism that arises dependent on the news services of the three largest groups of printed media in the country - O Estado de S. Paulo, Folha de S. Paulo and O Globo - which select themes, content, interpretations and analyzes of facts, not only for their daily editions, but feed newspapers on various regions of the country through their own agencies. The research is guided by the perspective of the sociology of newsrooms, which concentrates studies as newsmaking and gatekeeping, aiming to understand the modus operandi and actions of national news agencies in Brazilian journalism.

Key words: national news agencies, regional journalism, media conglomerates.

Resumen: En este artículo se muestra la presencia de agencias de noticias nacionales en 10 diferentes periódicos situados en las principales ciudades de Brasil, con el fin de dibujar un retrato del periodismo brasileño que se muestra dependiente de los servicios de noticias de los tres más grandes grupos de medios en el país - O Estado de S. Paulo, Folha de S. Paulo y $O$ Globo - que seleccionan temas y generan contenido, interpretaciones y análisis de los hechos, no sólo a sus periódicos, pero que, a través de sus propias agencias, alimentan periódicos en varias regiones del país. La investigación es guiada por la perspectiva de la sociología de los medios, que concentra una serie de estudios, como newsmaking y gatekeeping, a fin de comprender el modus operandi y el desempeño de las agencias de noticias nacionales en el periodismo brasileño. 
Palabras clave: agencias de noticias nacionales, periodismo regional, conglomerados de medios

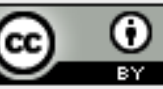

Esta obra está licenciada sob uma Licença Creative Commons

\section{INTRODUÇÃO}

Os jornais se apresentam todos iguais - afirmativa que não soa um exagero, muito menos uma falácia no cenário do jornalismo brasileiro contemporâneo. Entre os principais periódicos do eixo Rio-Paulo, a cobertura jornalística se restringe às mesmas pautas, ideias e assuntos, conforme apontam os resultados da pesquisa desta autora, voltada a identificar o modus operandi das agências de notícias nacionais no interior dos conglomerados de mídia brasileiros. A pesquisa mostra que $61,4 \%$ das notícias publicadas nas edições dos três grandes diários de circulação nacional são distribuídas antecipadamente a centenas de veículos assinantes dos serviços sediados em diversas cidades e regiões em diferentes Estados de Norte a Sul do País. Isto é, os jornais aproveitam os próprios conteúdos para alimentar, através de suas agências, as redações dos periódicos regionais assinantes desses serviços. $O$ Globo apresenta o maior índice de aproveitamento de conteúdos publicados em suas edições diárias, com 79,0\% nos despachos da $A G$; em segundo lugar, O Estado de S. Paulo, 62,0\%, através $A E$; e na terceira posição, a Folha de S. Paulo, 38,7\%, pela Folhapress.

A pesquisa se orienta pela perspectiva da sociologia das redações, ou dos produtores de notícias, que concentra um conjunto de pesquisas como newsmaketing e gatekeeping (TRAQUINA, 1993, 2000; WOLF, 1995; SOUSA, 2002; REESE e BALLINGER, 2001; PONTE, 2005; SHOEMAKER et. al. 2001; e SHOEMAKER, 2009), voltadas a compreender as rotinas produtivas dos media. A diferença das pesquisas sobre a produção de informação é que esses estudos "não se referem à cobertura de um acontecimento particular, mas ao andamento normal da cobertura informativa por períodos prolongados". (WOLF, 1995, p. 185).

Neste artigo, pretende-se mostrar a presença das agências de notícias nacionais nos diferentes jornais sediados nas principais capitais brasileiras, de forma a traçar um retrato do jornalismo brasileiro que se coloca dependente dos serviços noticiosos dos três maiores grupos de mídia impressa do País - O Estado de S. Paulo, Folha de S. Paulo e O Globo -, que selecionam temas e geram conteúdos, interpretações e análises dos fatos não só para suas edições diárias, mas através de suas próprias agências, alimentam jornais em diversas regiões 
do País, proprietários também de rádios e emissoras de televisão, compondo redes de meios de comunicação regionais.

\section{DA HEGEMÔNICA ATUAÇÃO DAS AGÊNCIAS NACIONAIS À AUSÊNCIA DE PLURALIDADE NO JORNALISMO BRASILEIRO}

Com essa constatação no primeiro momento, verificou-se então a incidência dos conteúdos das agências nos jornais em diferentes Estados brasileiros. A pesquisa consistiu na análise comparativa entre 10 jornais sediados nas principais capitais brasileiras. A amostragem compreende os jornais A Crítica (Manaus), O Liberal (Belém), O Popular (Goiânia), Correio Braziliene (Brasília), Estado de Minas (Belo Horizonte), Diário de Pernambuco (Recife), Diário do Nordeste (Fortaleza), A Tarde (Salvador), Gazeta do Povo (Curitiba) e Zero Hora (Porto Alegre). A escolha dos jornais foi orientada primeiramente pelo porte das capitais, classificadas pelo Instituto Brasileiro de Geografia e Estatística (IBGE); segundo, pela abrangência regional, tiragem e estrutura das redações. Conforme a proposta, foram coletados conteúdos (notícias e colunas assinadas) de abrangência nacional publicados nas editorias Política, Economia e Geral, no período de 4/10/2009 a 11/10/2009.

A coleta de textos das três editorias de temas nacionais ocorreu na tentativa de retratar a expressiva presença dos conteúdos das agências de notícias nos jornais em diferentes capitais. A leitura dos jornais revela que nem todos os veículos dão créditos à origem dos conteúdos de agências de notícias, isto é, ocultam aos leitores a procedência da notícia. A partir dessa constatação, foram adotados os seguintes critérios para coleta dos dados: a) conteúdos com assinaturas de repórteres, considerados, portanto, produção do próprio jornal; b) conteúdos com origem atribuídas às agências de notícias; e c) conteúdos nacionais sem assinaturas e origem não especificada.

No período do levantamento, foram identificados um total de 1.957 conteúdos nos 10 jornais de abrangência nacional, sendo 746 em Política; 880, Economia; e 331, Geral. (Tabela 1). Do total de 1.957 conteúdos, 747 (38,2\%) foram produzidos pelos próprios jornais; 512 (26,2\%), com origem das agências; e 698 (35,6\%), sem assinaturas ou origem não especificada.

Do total de 746 conteúdos de Política, 329 (44,1\%) foram produzidos pelos próprios jornais; 179 (24,0\%), das agências de notícias nacionais; e 238 (31,9\%), com origem não especificada. Entre os 880 conteúdos de Economia, 333 (37,8\%) com produção dos veículos; 
208 (23,6\%), dos serviços noticiosos; e 339 (38,5\%), sem origem especificada. Da soma de 331 conteúdos de Geral, 85 (25,7\%) apresentaram assinaturas dos jornais; 125 (37,8\%), conteúdos das agências; e 121 (36,5\%), com origem não especificada.

TABELA 1 - Total Geral de conteúdos das agências nacionais em 10 jornais brasileiros

\begin{tabular}{|c|l|c|c|c|c|c|c|c}
$\begin{array}{c}\text { Total Geral } \\
\text { em } 10 \text { jornais }\end{array}$ & $\begin{array}{c}\text { E ditoria } \\
\text { (nacional) }\end{array}$ & T otal & $\begin{array}{c}\mathbf{N}^{\circ} \text { de } \\
\text { conteúd os } \\
\text { produzidos } \\
\text { pelo jornal }\end{array}$ & $\%$ & $\begin{array}{c}\mathbf{N}^{\circ} \text { de } \\
\text { conteúd os } \\
\text { origem } \\
\text { agências }\end{array}$ & $\%$ & $\begin{array}{c}\mathbf{N}^{\circ} \text { de } \\
\text { conteúdos } \\
\text { origem não } \\
\text { especificada }\end{array}$ & $\%$ \\
\hline & Politica & 746 & 329 & 44,1 & 179 & 24,0 & 238 & 31,9 \\
\cline { 2 - 9 } & Economia & 880 & 333 & 37,8 & 208 & 23,6 & 339 & 38,5 \\
\cline { 2 - 9 } & Geral & $331 / 10$ a 11/10 & 85 & 25,7 & 125 & 37,8 & 121 & 36,5 \\
& Total & $\mathbf{1 9 5 7}$ & $\mathbf{7 4 7}$ & $\mathbf{3 8 , 2}$ & $\mathbf{5 1 2}$ & $\mathbf{2 6 , 2}$ & $\mathbf{6 9 8}$ & $\mathbf{3 5 , 6}$ \\
\hline
\end{tabular}

Fonte: da autora

*Notícias e colunas assinadas.

Do total geral de 1.957 conteúdos (entre notícias e colunas assinadas) de abrangência nacional das editorias de Política, Economia e Geral, 118 foram publicados em A Crítica; 197, n'O Liberal; 235, n'O Popular; 223, no Correio Braziliense; 193, no Estado de Minas; 150, no Diário de Pernambuco; 227, no Diário do Nordeste; 209, em A Tarde; 243, na Gazeta do Povo; e 162, no Zero Hora, no período de 4/10 a 11/10/2009. Entre os 10 jornais da amostragem, cinco (50\%) atribuem créditos autorais às notícias de agências de notícias nacionais: A Crítica, O Liberal, O Popular, A Tarde e Gazeta do Povo; quatro (40\%) não creditam autoria às notícias dos serviços noticiosos nacionais - exceto colunas assinadas; e apenas o Correio Braziliense (10,0\%) informa não ter assinatura dos serviços das agências nacionais.

\subsection{Jornais que atribuem créditos autorais às agências nacionais}

$\mathrm{O}$ texto a seguir retrata a presença das agências nacionais em cada jornal especificamente. A partir da observação empírica, os veículos foram reunidos em três grupos: 1) jornais que dão créditos autorais às agências; 2) jornais que não dão créditos autorais às agências; 3) e aqueles que operam com compartilhamento de conteúdos. Ao primeiro grupo, reuniram-se $A$ Crítica, $O$ Liberal, $O$ Popular, A Tarde e Gazeta do Povo; ao segundo grupo, Estado de Minas, Diário de Pernambuco, Diário do Nordeste e Zero Hora - todos 
confirmaram a assinatura dos serviços; 3) e ao terceiro, foram selecionados os jornais da amostragem que integram o consórcio Diários Associados, como Correio Braziliense, Estado de Minas e Diário de Pernambuco.

Entre os cinco veículos que fazem referência autoral à agências de notícias nacionais, foram contabilizados um total de 1.002 conteúdos provenientes de cobertura jornalística de abrangência nacional, entre notícias e colunas assinadas dispostas nas editorias Política, Economia e Geral. (Tabela 2). Do total geral, cerca de 270 (26,9\%) conteúdos foram identificados como produção própria do jornal; 497 (49,6\%) conteúdos provenientes das agências, registrados a partir da atribuição autoral exposta no texto; e 235 textos $(23,5)$ com origem não especificada ou sem assinaturas.

Entre os 1.002 textos, foram identificados 379 da editoria Política; 428 de Economia; e 195, Geral. Da editoria Política, foram contabilizados $125(33,0 \%)$ textos de produção própria dos jornais; 179 (47,2\%) textos provenientes das agências nacionais; e 75 (19,8\%), de origem não especificada, isto é, sem assinaturas. De Economia, somaram-se 121 (28,3\%) conteúdos produzidos pelos próprios jornais; 193 (45,1\%) provenientes das agências nacionais; e 114 (26,6\%) sem assinaturas.

TABELA 2 - Total Geral dos diários que dão créditos autorais às agências de notícias nacionais

\begin{tabular}{|c|l|c|c|c|c|c|c|c|}
\hline $\begin{array}{c}\text { Total Geral } \\
\text { dos jornais }\end{array}$ & $\begin{array}{c}\text { Editoria - } \\
\text { conteúdo } \\
\text { nacional }\end{array}$ & Total & $\begin{array}{c}\mathbf{N}^{\circ} \text { de } \\
\text { conteúdos } \\
\text { produzidos } \\
\text { pelo jornal }\end{array}$ & $\%$ & $\begin{array}{c}\mathbf{N}^{\circ} \text { de } \\
\text { conteúdos } \\
\text { origem } \\
\text { agências }\end{array}$ & $\%$ & $\begin{array}{c}\mathbf{N}^{\circ} \text { de } \\
\text { conteúdos } \\
\text { origem não } \\
\text { especificada }\end{array}$ & $\%$ \\
\hline \multirow{3}{*}{$(\mathbf{4} / \mathbf{1 0 ~ a}$} \\
$\mathbf{1 1 / 1 0 )}$ & Política & 379 & 125 & 33,0 & 179 & 47,2 & 75 & 19,8 \\
\cline { 2 - 9 } & Economia & 428 & 121 & 28,3 & 193 & 45,1 & 114 & 26,6 \\
\cline { 2 - 9 } & Geral & 195 & 24 & 12,3 & 125 & 64,1 & 46 & 23,6 \\
& Total & $\mathbf{1 0 0 2}$ & $\mathbf{2 7 0}$ & $\mathbf{2 6 , 9}$ & $\mathbf{4 9 7}$ & $\mathbf{4 9 , 6}$ & $\mathbf{2 3 5}$ & $\mathbf{2 3 , 5}$ \\
\hline
\end{tabular}

Fonte: da autora

*Notícias e colunas assinadas 
Em outras palavras, os dados acima revelam que a maioria $(49,6 \%)$ dos conteúdos de Política, Economia e Geral publicados nos jornais - entre aqueles que creditam referência às agências - são provenientes dos grupos Estado, Folha e $O$ Globo. A produção de conteúdos próprios, portanto, é relativamente muito baixa (26,9\%), considerando que um número expressivo de conteúdos não assinados $(23,5 \%)$ também inclui demais notícias das agências, como identificados pela pesquisa. Dos dados gerais, 118 textos relacionados à cobertura nacional foram publicados n'A Crítica; 197, n'O Liberal; 235, n'O Popular; 209, n'A Tarde; e 243, na Gazeta do Povo. (Tabela 3).

TABELA 3 - Diários que atribuem créditos autorais às agências nacionais 


\begin{tabular}{|c|c|c|c|c|c|c|c|c|}
\hline $\begin{array}{l}\text { Total Geral } \\
\text { dos jornais }\end{array}$ & $\begin{array}{l}\text { E ditoria - } \\
\text { conteúdo } \\
\text { nacional* }\end{array}$ & Total & $\begin{array}{c}\mathrm{N}^{\circ} \text { de } \\
\text { conteúdos } \\
\text { produzidos } \\
\text { pelo jornal }\end{array}$ & $\%$ & $\begin{array}{l}\mathrm{N}^{\circ} \text { de } \\
\text { conteúdos } \\
\text { origem } \\
\text { agências }\end{array}$ & $\%$ & $\begin{array}{c}\mathrm{N}^{\circ} \text { de } \\
\text { conteúdos } \\
\text { origem não } \\
\text { especificada }\end{array}$ & $\%$ \\
\hline \multirow{4}{*}{$\begin{array}{l}\text { A Crítica } \\
\begin{array}{c}(4 / 10 \mathrm{a} \\
11 / 10)\end{array}\end{array}$} & Politica & 34 & 6 & 17,6 & 18 & 53,0 & 10 & 29,4 \\
\hline & Economia & 44 & 18 & 41,0 & 1 & 2,2 & 25 & 56,8 \\
\hline & Geral & 40 & 0 & 0,0 & 26 & 65,0 & 14 & 35,0 \\
\hline & Total & 118 & 24 & 20,4 & 45 & 38,1 & 49 & 41,5 \\
\hline \multirow{4}{*}{$\begin{array}{l}\text { OL iberal } \\
\qquad \begin{array}{l}(4 / 10 \mathrm{a} \\
11 / 10)\end{array}\end{array}$} & Politica & 76 & 10 & 13,2 & 39 & 51,3 & 27 & 35,5 \\
\hline & Economia & 93 & 5 & 5,4 & 52 & 55,9 & 36 & 38,7 \\
\hline & Geral & 28 & 3 & 10,7 & 19 & 67,9 & 6 & 21,4 \\
\hline & Total & 197 & 18 & 9,1 & 110 & 55,9 & 69 & 35,0 \\
\hline \multirow{4}{*}{$\begin{array}{l}\text { O Popular } \\
\qquad \begin{array}{c}(4 / 10 \mathrm{a} \\
11 / 10)\end{array}\end{array}$} & Politica & 87 & 35 & 40,2 & 51 & 58,6 & 1 & 1,1 \\
\hline & Economia & 106 & 33 & 31,1 & 67 & 63,2 & 6 & 5,7 \\
\hline & Geral & 42 & 6 & 14,3 & 32 & 76,2 & 4 & 9,5 \\
\hline & Total & 235 & 74 & 31,5 & 150 & 63,8 & 11 & 4,7 \\
\hline \multirow{4}{*}{$\begin{array}{l}\text { A T arde } \\
(4 / 10 \mathrm{a} \\
11 / 10)\end{array}$} & Politica & 88 & 31 & 35,2 & 21 & 23,9 & 36 & 40,9 \\
\hline & Economia & 78 & 23 & 29,5 & 27 & 34,6 & 28 & 35,9 \\
\hline & Geral & 43 & 4 & 9,3 & 21 & 48,8 & 18 & 41,9 \\
\hline & Total & 209 & 58 & 27,8 & 69 & 33,0 & 82 & 39,2 \\
\hline \multirow{4}{*}{$\begin{array}{c}\text { Gazeta do } \\
\text { Povo } \\
(4 / 10 \text { a } \\
11 / 10)\end{array}$} & Politica & 94 & 43 & 45,7 & 50 & 53,2 & 1 & 1,1 \\
\hline & Economia & 107 & 42 & 39,3 & 46 & 43,0 & 19 & 17,6 \\
\hline & Geral & 42 & 11 & 26,2 & 27 & 64,3 & 4 & 9,5 \\
\hline & Total & 243 & 96 & 39,5 & 123 & 50,6 & 24 & 9,9 \\
\hline \multirow{4}{*}{$\begin{array}{c}\text { Total Geral } \\
\text { Jornais }\end{array}$} & Politica & 379 & 125 & 33,0 & 179 & 47,2 & 75 & 19,8 \\
\hline & Economia & 428 & 121 & 28,3 & 193 & 45,1 & 114 & 26,6 \\
\hline & Geral & 195 & 24 & 12,3 & 125 & 64,1 & 46 & 23,6 \\
\hline & Total & 1002 & 270 & 26,9 & 497 & 49,6 & 235 & 23,5 \\
\hline
\end{tabular}

Fonte: da autora

*Notícias e colunas assinadas

Entre os conteúdos nacionais identificados n'A Crítica, 24 (20,4\%) foram produzidos pelo próprio jornal; 45 (38,1\%), de origem das agências nacionais; e 49 (41,5\%), sem assinaturas ou especificação da origem. Quanto à divisão por áreas, o levantamento indica que 
no mesmo jornal foram publicados 34 textos relativos à editoria Política Nacional. Desse dado, $6(17,6 \%)$ conteúdos foram produzidos pelo veículo; 18 (53,0\%), com origem das agências nacionais; e 10 (29,4\%), sem assinaturas ou origem especificada. Da editoria Economia, foram identificados 44 textos: $18(41,0 \%)$ produzidos pelo próprio jornal; um (2,2\%) com origem das agências; e 25 (56,8\%) sem assinaturas ou origem especificada. Da editoria Geral, foram registrados 40 conteúdos: nenhum $(0,0 \%)$ produzido pelo jornal; 26 (65,0\%), de origem das agências nacionais; e 49 (41,5\%), sem assinaturas. Assim, os dados d'A Critica revelam que o maior percentual de notícias da cobertura nacional publicadas pelo diário é proveniente das agências $(38,1 \%)$. Em se tratando da cobertura política, por exemplo, o dado chega a $53,0 \%$. Ainda observa-se que nenhuma notícia da editoria Geral foi produzida pelo jornal, pois só das agências o percentual chega a $65,0 \%$; e $35,0 \%$ sem assinatura.

Os dados coletados n'O Liberal indicam que entre os 197 textos que compõem a amostragem, $18(9,1 \%)$ referem-se à produção própria do jornal; $110(55,9 \%)$ de origem das agências nacionais; e 69 (35\%), sem assinaturas ou origem especificada. Em relação à disposição por áreas, 76 textos foram publicados na editoria Política Nacional. Desse total; 10 $(13,2 \%)$ conteúdos identificados como produção do jornal; 39 (51,3\%) tiveram origem das agências nacionais; 27 (35,5\%), sem assinaturas ou origem não especificada. Da editoria de Economia, foram registrados 93 textos: cinco $(5,4 \%)$ com produção própria do jornal; 52 $(55,9 \%)$, com origem das agências de notícias; e $36(38,7)$, sem assinaturas ou origem não especificada. Da editoria Geral, foram contabilizados 28 textos: três $(10,7 \%)$ produzidos pelo próprio jornal; 19 (67,9\%), com origem das agências nacionais; e seis (21,4\%), sem assinaturas ou origem não especificada. Os dados d'O Liberal também confirmam a presença maior $(55,9 \%)$ de conteúdos das agências nacionais comparados aos de produção própria do periódico $(9,1 \%)$. O número de conteúdos de economia nacional publicados pelo jornal chega a ser relativamente maior em relação à política, por exemplo: de 93 conteúdos da primeira, 52 $(55,9 \%)$ provenientes das agências; contra 76 textos da segunda, $39(51,3 \%)$ com origem das agências.

N'O Popular, com 235 conteúdos registrados pelo levantamento, 74 (31,5\%) foram identificados como produção própria do jornal; 150 (63,8\%), com origem das agências nacionais; e 11 (4,7\%), sem assinaturas ou origem não especificada. Da editoria de Política Nacional, foram levantados 87 textos: 35 (40,2\%) produzidos pelo jornal; 51 (58,6\%), com origem das redações; e um $(1,1 \%)$ sem assinaturas. Quanto à editoria Economia, somaram-se 106 textos: 33 (31,1\%) identificados como produção do jornal; 67 (63,2\%), com origem das 
agências nacionais; e seis $(5,7 \%)$ sem origem especificada. Da editoria Geral, foram registrados 42 conteúdos: seis (14,3\%) produzidos pelo jornal; 32 (76,2\%) com origem das agências; e quatro $(9,5 \%)$ sem assinaturas. Comparativamente entre os quatro jornais que dão créditos autorais à agências nacionais, $O$ Popular apresenta o maior percentual $(63,8 \%)$ de notícias provenientes dos serviços noticiosos. Mas também em relação aos mesmos jornais, $O$ Popular ocupa o segundo lugar com percentual $(31,5 \%)$ de conteúdos de produção própria, perdendo a primeira posição somente pela Gazeta do Povo (39,5\%). No diário de Goiânia, os assuntos de economia provenientes de agências apresentam maior percentual $(63,2 \%)$ em relação aos de política $(58,6 \%)$, por exemplo.

N'A Tarde, com 209 textos identificados na amostragem, 58 (27,8\%) produzidos pelo próprio jornal; 69 (33,0\%), com origem das agências; e 82 (39,2\%) sem origem especificada. Desses dados, foram registrados 88 textos de Política Nacional: 31 (35,2\%), com produção própria da redação; 21 (23,9\%), com origem das agências; e 36 (40,9\%) sem assinaturas. Quanto à Economia, foram identificados 78 conteúdos: 23 (29,5\%) produzidos pelo jornal; 27 (34,6\%), com origem das agências; e 28 (35,9\%) sem origem especificada. Da área Geral, foram 43 textos: quatro $(9,3 \%)$, registrados como produção do jornal; 21 (48,8\%), com origem das agências; e 18 (41,9\%) sem origem especificada. Como único jornal do Nordeste - entre os três da mesma região que compõem a amostragem - que atribui créditos às agências de notícias nacionais, $A$ Tarde também confirma os dados gerais, isto é, o percentual de conteúdos de política, economia e geral publicados pelo jornal provenientes das agências é maior $(33,0 \%)$ em relação aos produzidos pela redação $(27,8 \%)$. Outro dado é que o percentual de assuntos de política de origem das agências se apresenta menor (23,9\%) em relação aos de economia (34,6\%). Em outras palavras, o percentual de conteúdos de política identificados como produção própria d'A Tarde se apresenta maior $(35,2 \%)$ em relação aos de economia (29,5\%), por exemplo.

Por último, na Gazeta do Povo, com 243 conteúdos da amostragem, 96 (39,5\%) foram identificados como produção própria do jornal; 123 (50,6\%), com origem das agências; e 24 (9,9\%), sem assinaturas. Entre os dados, 94 textos tratam de temas da política nacional: 43 $(45,7 \%)$ produzidos pelo jornal; 50 (53,2\%), com origem das agências; e um $(1,1 \%)$ sem assinatura. Da Economia Nacional, foram identificados 107 conteúdos: 42 (39,3\%) produzidos pelo jornal; $46(43,0 \%)$ com origem das agências nacionais; e 19 (17,6\%) sem origem especificada. Dos assuntos nacionais da editoria Geral, foram levantados 42 conteúdos: 11 (26,2\%) identificados como produção do jornal; 27 (64,3\%), com origem das 
agências nacionais; e quatro (9,5\%) sem origem especificada. $\mathrm{Na}$ Gazeta do Povo, os conteúdos de política, economia e geral provenientes das agências também apresentam maior percentual $(50,6 \%)$ em relação aos produzidos pelo jornal $(39,5 \%)$ diariamente. Os assuntos de política e economia com origem das agências apresentam maior percentual $(53,2 \%$ e $43,0 \%$, respectivamente) em relação aos identificados como produção própria do jornal (45,7\% e $39,3 \%$, respectivamente).

Em síntese, comparativamente, os cinco jornais que dão créditos autorais às agências se apresentam da seguinte forma em relação de conteúdos da cobertura nacional (Política, Economia e Geral) provenientes da Estado, Folhapress e O Globo: O Popular, com maior percentual (63,8\%); em segundo lugar, O Liberal (55,9\%); em terceiro, Gazeta do Povo (50,6\%); em quarto, A Crítica (38,1\%); e com menor percentual, A Tarde (33,0\%). Em relação aos textos relativos à cobertura nacional (Política, Economia e Geral) de produção própria, os jornais se apresentam da seguinte forma: Gazeta do Povo, com maior percentual (39,5\%); em segundo, O Popular, (31,5\%); em terceiro, $A$ Tarde (27,8\%); em quarto, $A$ Crítica (20,4\%); e com menor percentual, O Liberal $(9,1 \%)$. Os conteúdos da cobertura nacional sem assinaturas também se apresentam de forma expressiva nos diários: com maior percentual, A Crítica (41,5\%); em segundo, A Tarde, 39,2\%; em terceiro, O Liberal, (35,0\%); em quarto, Gazeta do Povo (9,9\%); e com menor percentual, O Popular (4,7\%). Ainda sobre os conteúdos da cobertura nacional publicados sem atribuição à origem, os dados indicam que, em três diários, o percentual é maior em relação aos textos identificados como produção própria: com maior percentual, $A$ Crítica, com 41,5\% sem assinaturas, contra 20,4\%, referentes à produção própria; com menor percentual, $A$ Tarde, 39,2\% referentes aos textos com origem não especificada, contra $27,8 \%$, da produção própria.

\subsection{Jornais que não atribuem créditos autorais às agências nacionais}

Estado de Minas, Diário de Pernambuco, Diário do Nordeste e Zero Hora compõem o grupo de jornais que, no procedimento de suas rotinas produtivas, optam por não creditar autoria às notícias de origem das agências nacionais. Desse conjunto, foram coletados 732 textos relativos à cobertura nacional das áreas Política, Economia e Geral: 317 (43,3\%) identificados como produção dos jornais; 15 (2,0\%) provenientes das agências nacionais somente colunas assinadas; e 400 (54,6\%) sem assinaturas. (Tabela 4).

Embora com a ausência de créditos autorais, os jornais confirmam a publicação de conteúdos provenientes da Estado, Folhapress e $O$ Globo. Os dados referentes a créditos de 
autorias às agências apresentados a seguir foram identificados, especificamente, nas colunas assinadas. De Política, foram coletados 273 textos: 124 (45,4\%), produção dos jornais; nenhum (0,0\%) proveniente das agências; e 149 (54,6\%) sem assinaturas. De Economia, foram 378 conteúdos registrados: 168 (44,4\%), produção dos jornais; 15 (4,0\%), com origem das agências - somente colunas assinadas; e 195 (51,6\%), sem assinaturas. Da editoria Geral, foram 81 textos coletados: 25 (30,9\%) identificados como produção do jornal; nenhum $(0,0 \%)$ com origem das agências; e $56(69,1 \%)$, sem assinaturas.

TABELA 4 - Jornais que não atribuem créditos autorais às agências de notícias nacionais

\begin{tabular}{|c|c|c|c|c|c|c|c|c|}
\hline $\begin{array}{l}\text { Total Geral } \\
\text { dos jornais }\end{array}$ & $\begin{array}{l}\text { Editoria - } \\
\text { conteúdo } \\
\text { nacional* }\end{array}$ & Total & $\mid \begin{array}{c}\mathbf{N} \text { de } \\
\text { conteúdos } \\
\text { produzid os } \\
\text { pelo jornal }\end{array}$ & $\%$ & $\begin{array}{c}\mathrm{N}^{\circ} \text { de } \\
\text { conteúd os } \\
\text { origem das } \\
\text { agências }\end{array}$ & $\%$ & $\begin{array}{c}\mathrm{N}^{\circ} \mathrm{de} \\
\text { or igem não } \\
\text { especificad a }\end{array}$ & $\%$ \\
\hline \multirow{4}{*}{$\begin{array}{c}\text { Estado de } \\
\text { Minas } \\
\\
(4 / 10 \mathrm{a} \\
11 / 10)\end{array}$} & Politica & 67 & $53^{* *}$ & 79,1 & 0 & 0,0 & 14 & 20,9 \\
\hline & Economia & 87 & $46^{* *}$ & 52,9 & 2 & 2,3 & 39 & 44,8 \\
\hline & Geral & 39 & $8^{* \pi}$ & 20,5 & 0 & 0,0 & 31 & 79,5 \\
\hline & Total & 193 & $107^{* *}$ & 55,4 & 2 & 1,0 & 84 & 43,5 \\
\hline \multirow{4}{*}{$\begin{array}{c}\text { Diário de } \\
\text { Pernambuco } \\
(4 / 10 \mathrm{a} \\
11 / 10)\end{array}$} & Politica & 54 & $29^{* *}$ & 53,7 & 0 & 0,0 & 25 & 46,3 \\
\hline & Economia & 69 & $39 * *$ & 56,5 & 6 & 8,7 & 24 & 34,8 \\
\hline & Geral & 27 & $14^{* *}$ & 51,9 & 0 & 0,0 & 13 & 48,1 \\
\hline & Total & 150 & $82 \div *$ & 54,7 & 6 & 4,0 & 62 & 41,3 \\
\hline \multirow{4}{*}{ 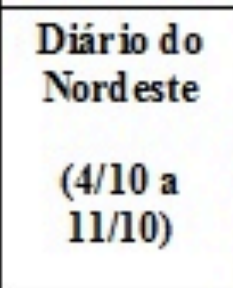 } & Politica & 78 & 12 & 15,4 & 0 & 0,0 & 66 & 84,6 \\
\hline & Economia & 137 & 56 & 40,9 & 5 & 3,6 & 76 & 55,5 \\
\hline & Geral & 12 & 3 & 25,0 & 0 & 0,0 & 9 & 75,0 \\
\hline & Total & 227 & 71 & 31,3 & 5 & 2,2 & 151 & 66,5 \\
\hline \multirow{4}{*}{$\begin{array}{l}\text { Zero Hor a } \\
\qquad \begin{array}{c}(4 / 10 \text { a } \\
11 / 10)\end{array}\end{array}$} & Politica & 74 & 30 & 40,5 & 0 & 0,0 & 44 & 59,5 \\
\hline & Economia & 85 & 27 & 31,8 & 2 & 2,4 & 56 & 65,8 \\
\hline & Geral & 3 & 0 & 0,0 & 0 & 0,0 & 3 & 100,0 \\
\hline & Total & 162 & 57 & 35,2 & 2 & 1,2 & 103 & 63,6 \\
\hline \multirow{4}{*}{$\begin{array}{c}\text { Total Geral } \\
\text { Jornais } \\
(4 / 10 \mathrm{a} \\
11 / 10)\end{array}$} & Politica & 273 & 124 & 45,4 & 0 & 0,0 & 149 & 54,6 \\
\hline & Economia & 378 & 168 & 44,4 & 15 & 4,0 & 195 & 51,6 \\
\hline & Geral & 81 & 25 & 30,9 & 0 & 0,0 & 56 & 69,1 \\
\hline & Total & 732 & 317 & 43,3 & 15 & 2,0 & 400 & 54,6 \\
\hline
\end{tabular}


Fonte: da autora

*Notícias e colunas assinadas ** Integrantes dos Diários Associados: Braziliense, Estado de Minas e Diário de Pernambuco operam com compartilhamento de conteúdos.

O Estado de Minas apresentou 193 textos no período da amostragem: 107 (55,4\%) identificados como produção do jornal; dois (1,0\%) de origem das agências; e 84 (43,5\%) sem assinaturas. Do total, 67 foram identificados na editoria Política: $53(79,1 \%)$ referentes à produção própria; nenhum $(0,0 \%)$ de origem das agências nacionais; e 14 (20,9\%) sem assinaturas. Da editoria Economia, foram registrados 87 conteúdos: 46 (52,9\%) da própria redação; dois $(2,3 \%)$ provenientes das agências nacionais; e 39 (44,8\%) sem origem especificada. Da editoria Geral, foram identificados 39 textos: oito $(20,5 \%)$ produzidos pelo jornal; nenhum $(0,0 \%)$ de origem das agências nacionais; e 31 (79,5\%) sem assinaturas.

Cerca de 150 textos da amostragem foram registrados no Diário de Pernambuco: 82 $(54,7 \%)$ identificados como produção do próprio jornal; seis $(4,0 \%)$ com origem das agências; e $62(41,3 \%)$ sem origem especificada. Do total, foram identificados 54 conteúdos da editoria Política: 29 (53,7\%) produzidos pelo jornal; nenhum $(0,0 \%)$ de origem das agências; e 25 (46,3\%) sem origem especificada. Da editoria de Economia, foram registrados 69 textos: 39 $(56,5 \%)$ produzidos pelo jornal; seis $(8,7 \%)$ com origem das agências nacionais; e 24 (34,8\%) sem assinaturas. Na editoria Geral, foram coletados 27 conteúdos: 14 (51,9\%) produzidos pela própria redação; nenhum $(0,0 \%)$ com origem das agências nacionais; e $13(48,1 \%)$ sem origem especificada.

O Diário do Nordeste compôs 227 textos da amostragem: 71 (31,3\%) identificados como produção do próprio jornal; cinco $(2,2 \%)$ de origem das agências nacionais; e 151 $(66,5 \%)$, sem assinaturas especificadas. Do total, foram identificados 78 conteúdos de política: $12(15,4 \%)$ produzidos pelo jornal; nenhum $(0,0 \%)$ de origem das agências; e 66 $(84,6 \%)$ sem origem especificada. Da editoria Economia, foram coletados 137 textos: 56 (40,9\%) produzidos pelo jornal; cinco $(3,6 \%)$ de origem das agências; e 76 (55,5\%) sem assinaturas. Quanto à editoria Geral: foram registrados 12 conteúdos: três $(25,0 \%)$ produzidos pelo jornal; nenhum $(0,0 \%)$ de origem das agências; e nove $(75,0 \%)$ sem assinaturas.

Do Zero Hora, somaram-se 162 textos à amostragem: 55 (35,2\%) identificados como produção do próprio jornal; dois $(1,2 \%)$ de origem das agências; $103(63,6 \%)$ sem assinaturas. Desse total, foram coletados 74 conteúdos de Política: 30 (40,5\%) identificados como produção do jornal; nenhum $(0,0 \%)$ de origem das agências; e 44 (59,5\%) sem assinaturas ou origem especifica. Da editoria Política, foram coletados 85 textos: 27 (31,8\%) identificados 
como produção do próprio jornal; dois $(2,4 \%)$ com origem das agências; e $56(65,8 \%)$ sem assinaturas ou origem especificada. Quanto à editoria Geral, foram coletados três textos: nenhum $(0,0 \%)$ identificado como produção do jornal; nenhum $(0,0 \%)$ de origem das agências; e três $(100,0 \%)$ sem assinaturas ou origem especificada.

Em síntese, comparativamente, os quatro jornais que não dão créditos autorais às agências se apresentam da seguinte forma em relação aos conteúdos da cobertura nacional (Política, Economia e Geral) identificados como produção própria: Estado de Minas, com maior percentual, 55,4\%; Diário de Pernambuco, em segundo (54,7\%); Zero Hora, em terceiro (35,2\%); e Diário do Nordeste, com menor percentual de textos de produção própria. Em relação aos textos não assinados ou sem origem especificada, os jornais se apresentam da seguinte forma: Diário do Norte, com maior percentual (66,5\%); Zero Hora, em segundo (63,6\%); Estado de Minas, em terceiro (43,5\%); e Diário de Pernambuco, com menor percentual de conteúdos sem assinaturas (41,3\%). Quanto aos conteúdos com créditos autorais às agências - na maioria, colunas assinadas, os diários ocupam as seguintes posições: Diário de Pernambuco, com maior percentual (4,0\%); Diário do Nordeste, em segundo (2,2\%); Zero Hora, em terceiro (1,2\%); e Estado de Minas, o menor percentual $(1,0 \%)$ referente aos conteúdos atribuídos às agências nacionais. O levantamento revela ainda que, em dois diários, os conteúdos da cobertura nacional (Política, Economia e Geral) sem origem especificada ou sem assinaturas apresentam percentuais maiores em relação aos identificados como produção própria. O primeiro, Diário do Nordeste, com maior percentual $(66,5 \%)$ de conteúdos sem assinaturas, contra 31,3\% registrados como produção própria; e Zero Hora, com percentual de $63,6 \%$ para textos sem assinaturas, contra $35,2 \%$ relativos à produção própria.

\subsection{Compartilhamento de conteúdos}

Entre os 10 veículos da amostragem da pesquisa, apenas o $C B$ afirma não ter contrato com as agências nacionais - encerrado em meados de 2009, conforme informações da própria redação. O diário foi mantido na amostragem devido ao critério de seleção dos jornais para composição do corpus da pesquisa e, consequentemente, por constatar o sistema interno de compartilhamento de informações entre os veículos Associados, que compõem o levantamento desta pesquisa.

A amostragem revelou um número considerável de conteúdos comuns publicados na íntegra - notícias e colunas assinadas da cobertura nacional - no $C B, E M$ e $D P E$. Segundo as 
respectivas redações, trata-se de um procedimento interno de compartilhamento de informações entre os veículos (emissoras de rádio e TV's, jornais impressos e online) Associados com sede em diferentes cidades do País.

Entre os três diários, o $C B$ apresentou o maior percentual de conteúdos da cobertura nacional identificados como produção própria (71,7\%); em segundo, $E M, 55,4 \%$; e em terceiro, $D P E$, com $54,7 \%$. Quanto aos conteúdos com indicação às agências, o DPE fica em primeira posição, com 4,0\%; o $E M$, em segundo, com $1,0 \%$; e o $C B$, que não mantém contratos com as agências, fica em terceiro, com 0,0\%. Em contrapartida, os diários apresentam percentuais expressivos quanto aos conteúdos sem origem especificada ou sem assinaturas: $E M$ lidera, com 43,5\%; em segundo, $D P E$, com 41,3\%; e em terceira posição, $C B$, $\operatorname{com} 28,3 \%$.

A análise comparativa entre $C B, E M$ e $D P E$ revelou que, do total de 349 conteúdos identificados como produção das respectivas redações, 225 (64,5\%) não foram compartilhados internamente; e $124(25,5 \%)$ compartilhados, conforme período da amostragem (4/10 a 11/10). (Tabela 5). Embora o aproveitamento de informações ocorra entre todos os jornais do grupo, segundo informações das três redações citadas, observou-se que o maior número de textos publicados parte do Correio Braziliense para os demais, no caso da cobertura de política e economia nacional, levando em conta a estrutura do próprio jornal e dos Diários Associados na Capital Federal.

Separadamente, o Correio Braziliense publicou um total de 160 textos das três editorias, identificados como produção da redação: $103(64,4 \%)$ não compartilhados no período da amostragem; e 57 (35,6\%) compartilhados. De Política, foram identificados 80 conteúdos: $43(53,7 \%)$ não compartilhados no período da coleta de dados; e 37 (46,3\%) compartilhados. De Economia, 44 textos coletados: 33 (75,0\%) não compartilhados; e 11 $(25,0 \%)$ compartilhados. Da editoria de Geral, foram identificados 36 conteúdos: $27(75,0 \%)$ não compartilhados; e nove $(25,0 \%)$ compartilhados.

No caso do Estado de Minas, foram 107 textos das três editorias identificados como produção da redação: $65(60,7 \%)$ não compartilhados; e 42 (39,3\%) compartilhados no período da coleta de dados. Da editoria Política, foram coletados 52 textos: 28 (53,8\%) não compartilhados e 24 (46,2\%) não compartilhados; de Economia, 47 conteúdos: 34 (72,3\%) não compartilhados; e $13(27,7 \%)$ compartilhados; e de Geral, 8 conteúdos no total: três $(37,7 \%)$ não compartilhados; e cinco $(62,5 \%)$, compartilhados. 
TABELA 5 - Conteúdos compartilhados pelos Diários Associados

\begin{tabular}{|c|c|c|c|c|c|c|}
\hline E dição & $\begin{array}{l}\text { E ditoria } \\
\text { (conteúd o } \\
\text { nacional) }\end{array}$ & $\begin{array}{l}\text { Conteúdos } \\
\text { produzidos } \\
\text { pelo jornal }\end{array}$ & $\begin{array}{l}\mathrm{N}^{\circ} \text { de conteúdos não } \\
\text { compartillhad os } \\
\text { Diários Associados }\end{array}$ & $\%$ & $\begin{array}{c}\mathrm{N}^{\circ} \text { de conteúdos } \\
\text { compartilhados } \\
\text { Diários } \\
\text { Associados }\end{array}$ & $\%$ \\
\hline \multirow{4}{*}{$\begin{array}{c}\text { Correio } \\
\text { Braziliense } \\
(4 / 10 \text { a } 11 / 10)\end{array}$} & Politica & 80 & 43 & $\mathbf{5 3 , 7}$ & 37 & 46,3 \\
\hline & Economia & 44 & 33 & 75,0 & 11 & 25,0 \\
\hline & Geral & 36 & 27 & 75,0 & 9 & 25,0 \\
\hline & Total & 160 & 103 & 64,4 & 57 & 35,6 \\
\hline \multirow{4}{*}{$\begin{array}{c}E \text { stado de } \\
\text { Minas } \\
(4 / 10 \text { a } 11 / 10)\end{array}$} & Politica & 52 & 28 & $\mathbf{5 3}, 8$ & 24 & 46,2 \\
\hline & Economia & 47 & 34 & 72,3 & 13 & 27,7 \\
\hline & Geral & 8 & 3 & 37,5 & 5 & 62,5 \\
\hline & Total & 107 & 65 & 60,7 & 42 & 39,3 \\
\hline \multirow{4}{*}{$\begin{array}{c}\text { Diário de } \\
\text { Pernambuco } \\
(4 / 10 \text { a } 11 / 10)\end{array}$} & Politica & 29 & 17 & 58,6 & 12 & 41,4 \\
\hline & Economia & 39 & 35 & 89,7 & 4 & 10,3 \\
\hline & Geral & 14 & 5 & 35,7 & 9 & 64,3 \\
\hline & Total & 82 & 57 & 69,5 & 25 & 30,5 \\
\hline \multirow{4}{*}{$\begin{array}{c}\text { Diários } \\
\text { Associados } \\
\text { TotalGeral } \\
(4 / 10 \text { a } 11 / 10)\end{array}$} & Politica & 161 & 88 & 54,7 & 73 & 45,3 \\
\hline & Economia & 130 & 102 & 78,5 & 28 & 21,5 \\
\hline & Geral & 58 & 35 & 60,3 & 23 & 39,7 \\
\hline & Total & 349 & 225 & 64,5 & 124 & 35,5 \\
\hline
\end{tabular}

Fonte: da autora

Já no Diário de Pernambuco, foram 82 conteúdos das três editorias registrados como produção da redação: $57(69,5 \%)$ não compartilhados e 25 (30,5\%) compartilhados no período da amostragem. De Política, foram coletados 29 conteúdos da redação: 17 (58,6\%) não compartilhados e 12 (41,4\%) compartilhados; de Economia, 39 textos: 35 (89,7\%) não compartilhados e quatro (10,3\%) compartilhados; de Economia, 14 conteúdos: cinco $(35,7 \%)$ não compartilhados e nove $(64,3 \%)$ compartilhados. 
Em síntese, entre os três Associados, o Estado de Minas apresenta o maior índice (39,3\%) de conteúdos da cobertura nacional - Política, Economia e Geral - compartilhados; em segundo, vem o Correio Braziliense, com 35,6\%; e o Diário de Pernambuco em terceiro, com 30,5\%. Quanto aos conteúdos da cobertura nacional produzidos pelos três jornais não compartilhados, o $D P E$ lidera, com 69,5\%; em segundo, $C B$, com 64,4\%; e $E M$, em terceiro, com $60,7 \%$.

Por fim, os dados da pesquisa revelam que $46,3 \%$ do conteúdo jornalístico nacional publicado pelo Estado de Minas e 41,4\% pelo Diário de Pernambuco partem essencialmente do sistema de compartilhamento do Correio Braziliense. Os dados comprovam ainda que $42,2 \%$ das matérias jornalísticas de Política Nacional do $C B$ são publicadas diariamente pelo $E M$ ou $D P$. Assim, a conformidade na cobertura Política Nacional por parte do $C B$ em relação aos três jornais do eixo Rio/São Paulo afeta diretamente os demais Diários Associados, que se colocam dependentes, não das agências nacionais, mas do sistema de compartilhamento de informações jornalísticas predominante no interior do Grupo.

\section{CONSIDERAÇÕES}

As constatações apresentadas por esta pesquisa sobre o jornalismo de agências praticado de Norte a Sul do País revelam tanto a presença hegemônica de três grandes grupos de mídia brasileiro pautando cotidianamente centenas de veículos sediados em diferentes regiões, quanto à ausência de pluralidade na cobertura jornalística nacional. Os serviços de agências atendem não só ao noticiário básico de política, economia e assuntos gerais conforme a coleta de dados -, mas, pelo contrário, estendem a diversos pacotes, como os chamados 'especiais', os quais, na lógica de aproveitamento de conteúdos exclusivos produzidos para os principais jornais dos três maiores conglomerados de mídia, são ofertados por suas respectivas agências aos veículos assinantes.

De um modo geral a cobertura jornalística nas diferentes regiões acaba sendo orientada pelas decisões e posições editorias d'OESP, FSP e $O$ Globo. O cardápio diário de notícias prontas que perpassam pelos mesmos temas selecionados e produzidos por três influentes jornais faz com que nem mesmo estruturas arrojadas do porte de Zero Hora não acabem afetadas pelas facilidades da prestação de serviços em rede digital, portanto veloz, das agências nacionais.

O que se confirma nesta pesquisa é que a presença de mesmos temas, conteúdos e interpretações se estendem às demais redações do país através dos serviços de distribuição de 
conteúdos, completando assim o funil midiático em três níveis: 1) seleção e produção pelos três jornais - Estado, Folha e $O$ Globo; 2) distribuição através das respectivas agências $-A E$, Folhapress e $A G$; e 3 ) reprodução por diversas redações em diferentes regiões brasileiras.

\section{REFERÊNCIAS BIBLIOGRAFICAS}

PONTE, Cristina. Para entender as notícias. Linhas de análise do discurso jornalístico. Florianópolis: Insular, 2005.

REESE, Stephen D. e BALLINGER, Jane. The roots of a Sociology of News: Remembering Mr. Gates and social control in the newsroom. In.: J\&MC Quarterly. Vo. 78, No. 4, Winter 2001. p. 641-658.

SHOEMAKER J. Pamela, e VOS, Tim P. Gatekeeping theory. Routledge: Nova York, 2009.

SHOEMAKER, Pamela J.; EICHHOLZ, Martin; KIM, Eunyi; and WRIGLEY, Brenda. Individual and routine forces in gatekeeping. In.: J\&MC Quarterly. V. 78, No. 2, Summer 2001. p. 233-246.

SOUSA, Jorge Pedro. Teorias da notícia e do jornalismo. Florianópolis: Chapecó, 2002.

TRAQUINA, Nelson. Jornalismo: questões, teorias e “estórias” (org.). Lisboa: Vega, 1993. . (org.). Jornalismo 2000. Revista de Comunicação e Linguagens. Universidade Nova de Lisboa. Lisboa: Relógio D’Agua. n 27, fev. 2000.

WOLF, Mauro. Teorias da comunicação. 4. ed. Lisboa: Presença, 1995.

Original recebido em: 20/12/2013

Aceito para publicação em: 20/11/2014

Resumo sobre a autora:

Professora do Curso de Jornalismo e do Mestrado em Jornalismo da UEPG, atualmente é coordenadora da graduação. Possui doutorado em

Ciências da Comunicação, pela Unisinos (2010), mestrado em

Comunicação, pela Umesp (2002), e graduação em Comunicação/ Jornalismo, pela UFJF (1992). 
